\title{
Assessment of body composition in Sri Lankan children: validation of a skin fold thickness equation
}

\author{
V P Wickramasinghe ${ }^{1}$, S P Lamabadusuriya ${ }^{1}$, G J Cleghorn ${ }^{2}$ and P S W Davies ${ }^{2}$
}

\begin{abstract}
Background Morbidity associated with obesity is related to the fat mass (FM) of the body. The direct estimation of FM is difficult. Skin fold thickness (SFT) is a simple and cheap alternative for accurate assessment of FM, and population specific equations are necessary for accurate assessment of FM using SFT.
\end{abstract}

Objective To develop a SFT prediction equation to estimate FM of Sri Lankan children.

Design, setting and method A cross-sectional descriptive study was done at the University Paediatric Unit of Lady Ridgeway Hospital, Colombo. Data were collected from 5 to 15 year old healthy children. Triceps, biceps, supra-iliac and subscapular SFT were measured using Harpendens skin fold caliper. Total body water was assessed using an isotope dilution method $\left(\mathrm{D}_{2} \mathrm{O}\right)$, and fat free mass calculated. FM was assessed based on 2 compartment body composition model. Multiple regression analysis was used to develop prediction equation and validated using PRESS (prediction of sum of squares) statistical technique. Independent variables were age, triceps SFT, subscapular SFT and sex.

Results Prediction equation for FM $[(0.68 \times a g e)+$ $(0.246 \times$ triceps SFT $)+(0.383 \times$ subscapular SFT $)-$ (1.61×sex code) -3.45 ] was able to predict $76.4 \%$ of variance with a root mean squared error (RMSE) of 3.4 $\mathrm{kg}$. PRESS statistics was $3.4 \mathrm{~kg}$ with press residuals of $1.56 \mathrm{~kg}$. Bland-Altman technique showed that the majority of the residuals were within mean bias $\pm 1.96 \mathrm{SD}$.

Conclusion Results of this study provide an SFT equation for the prediction of FM in Sri Lankan children.

\section{Introduction}

Assessment of body fat mass (FM) and fat free mass (FFM) is important in the management of many illnesses like obesity, cardiovascular diseases and type 2 diabetes mellitus. However, sophisticated methods are expensive, need trained staff and could be cumbersome to individuals especially children. Simple anthropometric procedures would be more useful. SFT is a method that would be useful in body composition assessment in low income countries [1].
SFT is superior to mid-arm circumference for health screening as it will avoid errors due to soft tissue compression. SFT measurements can be done with better accuracy [1]. There are many regression equations developed to assess body composition. However, there are no prediction equations that are validated on populations of south Asian origin. Some of these prediction equations had been cross validated on other populations with mixed results $[2,3]$. Several published SFT equations were cross-validated on a group of Sri Lankans and a group of Sri Lankan migrant children living in Australia, and results showed poor agreement with reference values $[4,5]$. Absence of a validated SFT equation on Sri Lankans or south Asians has limited its use. We have validated an SFT equation to be used on Sri Lankan children.

\section{Materials and methods}

Five to 15-year old healthy Sri Lankan children were recruited from 3 schools in Colombo with a fair representation of all socio-economic groups. The study was conducted at the clinical laboratory of the University Paediatric Unit of Lady Ridgeway Hospital for Children, Colombo, Sri Lanka from September 2004 to April 2005. Informed written consent from parents and assent from children were obtained. The Ethical Review Committees of the University of Colombo and the Lady Ridgeway Hospital for Children approved the study.

Height was measured with a wall-mounted stadiometer to the last completed $0.1 \mathrm{~cm}$ (Surgical and Medical Products, Australia) and weight was measured to the closest $100 \mathrm{~g}$ using an electronic weighing scale (Soehnle, Soehnle-Waagen $\mathrm{GmbH} \& \mathrm{Co}$, Germany). SFT was measured using a Harpenden Skinfold Caliper (John Bull, British Indicators Ltd, UK) to the closest $1 \mathrm{~mm}$ on the left side of the body. Triceps, biceps, subscapular (SS) and suprailiac (SI) SFT were measured using standard protocol [6].

Total body water (TBW) was measured by an isotope dilution method using deuterium in the form of water $\left(\mathrm{D}_{2} \mathrm{O}\right)$. Initially a sample $(10 \mathrm{ml})$ of urine was collected in a screw cap bottle. This was used to determine the

${ }^{1}$ Department of Paediatrics, Faculty of Medicine, University of Colombo, Kynsey Road, Colombo 08, ${ }^{2}$ Children's Nutrition Research Centre, Department of Paediatrics and Child Health, University of Queensland, Brisbane, Australia. Correspondence: VPW, e-mail <pujithaw@yahoo.com>. Received 25 January and revised version accepted 7 August 2008. Competing interests: none declared. 
basal deuterium level in the body. A dose of $0.5 \mathrm{~g} / \mathrm{kg}$ body weight of a $10 \% \mathrm{D}_{2} \mathrm{O}$ solution, was given orally and the dose was measured to $0.01 \mathrm{~g}$ [7]. A second sample of urine was collected 4-6 hours after giving deuterium, allowing it to equilibrate with body water. The urine samples were stored in tight screw cap containers, at $4^{\circ} \mathrm{C}$ and air freighted to Children's Nutrition Research Centre, University of Queensland, Brisbane, Australia in batches for the assessment of $\mathrm{D}_{2} \mathrm{O}$ levels using isotope ratio mass spectrometry. The technique of calculating TBW is described elsewhere [8]. From TBW the FFM was calculated using age and gender specific water content of FFM [9].

$$
\text { FFM }=\frac{\text { TBW }}{\text { Percent water in FFM }}
$$

The absolute FM was calculated by subtracting FFM from weight based on the two-compartment body composition model. Percent FM refers to FM expressed as a fraction of body weight.

Three hundred and nineteen children were recruited and 282 data sets were used in the final analysis. They were randomly assigned to a validation group (188; M/F: 105/83) and a cross-validation group (94; M/F:53/41).

Prediction equations were constructed using the backward elimination method of stepwise multiple regression analysis. Prediction equations were constructed separately, taking FM and \%FM as the dependent variable, and age, sex code using binary dummy variables (male $=1$ and female $=0$ ) and each SFT as the possible independent variables. Statistical methods including calculation of sample size are described elsewhere [10]. Based on these statistical methods, separate preliminary equations were formulated to estimate FM and \%FM. Predictability of the equations was evaluated using the cross validation group. Pure error was used to evaluate the predictability of the derived equation when applied to the cross validation group [10]. Final prediction equation was derived after combining both groups together based on the independent variables determined by preliminary equations. Final gender combined SFT equations were statistically validated using PRESS (prediction of sum of squares) statistical method. Based on the method described by Bland and Altman, agreement between prediction equation and criterion method was evaluated [11].

Statistical analyses were done using NCSS 2000 (Hintze JL, Kayswille, Utah, USA) statistical computer packages. Parameters were compared between gender groups using unpaired t-test. $\mathrm{P}<0.05$ was considered as significant based on two tailed t-test.

\section{Results}

There were 105 boys and 83 girls in the validation group and 53 boys and 41 girls in the cross-validation group. Table 1 shows the demographic characteristics of the two groups. There were no statistically significant differences between the groups when compared across gender. Multiple regression was performed using FM and $\%$ FM as dependant variables, and age, sex code and SFT as independent variables. Age, sex code, triceps and subscapular SFT were shown as the most reliable independent variables for the prediction of both FM and $\% \mathrm{FM}$.

Two separate sets of preliminary equations were constructed for the prediction of FM and \%FM (table 2). In each set there was a gender nonspecific and gender specific equation. Gender nonspecific equation had a higher coefficient of determination in the prediction of both FM and \%FM than gender specific equations. But RMSE did not differ significantly in any of these equations.

Cross-validation results of the preliminary equations are shown in table 3 along with the values obtained by criterion method $\left(\mathrm{D}_{2} \mathrm{O}\right)$. Mean FM and \%FM assessed by all equations, in both males and females did not differ significantly from each other. However, the gender nonspecific equation gave minimum bias and minimum pure error than gender specific equations for the assessment of FM in both groups. For the assessment of $\% \mathrm{FM}$, gender nonspecific equation gave low bias but high pure error when compared with gender specific equation. Gender nonspecific equation for the assessment of FM either under or over predicted by amounts less than $1000 \mathrm{~g}$. Similarly gender nonspecific equation for the prediction of $\% \mathrm{FM}$ also had prediction accuracy within $1.1 \%$ units. A statistically significant $(\mathrm{p}<0.001)$ association existed between criterion method and the predicted values of FM and $\% \mathrm{FM}$ assessed by each of the new prediction equations (table 3 ).

Table 4 shows the final prediction equation derived using the entire group of 282 individuals (male 158 and female 124). The coefficient of determination and RMSE showed a good agreement between independent variables (age, sex code, triceps and subscapular SFT) and the dependent variables (FM and \%FM). Although statistically significant, the strength of $\mathrm{R}^{2}$ for $\% \mathrm{FM}(46.9 \%)$ was low compared to the prediction of FM $(76.4 \%)$. PRESS statistics were similar to pure error in the cross validation of preliminary equations. However, PRESS residuals were slightly higher than mean bias of cross validation group for the prediction of both FM and \%FM.

$\mathrm{FM}$ and $\% \mathrm{FM}$ predicted by each final prediction equation was plotted against the FM and \%FM assessed by the criterion method (figure 1a and 1c). A high association was seen between FM assessed by the equation and criterion method. Figure $1 \mathrm{~b}$ shows the Bland and Altman plot for mean FM assessed by the criterion method and final prediction equation and bias between criterion method and final prediction equation. Most of the bias was close to zero. Figure 1d shows the Bland and Altman plot for the assessment of $\% \mathrm{FM}$. In contrast to FM assessment, bias was more dispersed. 
Table 1. Demographic characteristics of validation and cross-validation groups by gender

\begin{tabular}{lll}
\hline Male & Validation group Mean $(\mathrm{SD})$ & Cross validation group Mean $(\mathrm{SD})$ \\
\hline $\mathrm{N}$ & 105 & 53 \\
Age $(\mathrm{years})$ & $9.5(2.7)$ & $9.6(2.7)$ \\
Weight $(\mathrm{kg})$ & $31.1(11.7)$ & $31.3(14.0)$ \\
Height $(\mathrm{cm})$ & $134.5(14.9)$ & $134.6(16.8)$ \\
BMI $\left(\mathrm{kgm}^{-2}\right)$ & $16.7(3.6)$ & $16.5(4.1)$ \\
FM $(\mathrm{kg})$ & $8.7(5.9)$ & $9.3(7.8)$ \\
Percentage FM $(\%)$ & $26.0(9.8)$ & $26.2(12.0)$ \\
Triceps SFT & $12.4(6.2)$ & $12.2(7.6)$ \\
Subscapular SFT & $11.4(8.7)$ & $11.6(9.9)$ \\
Supra-iliac SFT & $15.8(10.8)$ & $15.6(12.6)$ \\
Biceps SFT & $7.8(8.7)$ & $7.8(5.6)$ \\
\hline Female & & \\
\hline N & 83 & 41 \\
Age (years) & $10.1(2.8)$ & $10.1(2.8)$ \\
Weight $(\mathrm{kg})$ & $34.7(12.6)$ & $35.5(13.0)$ \\
Height $(\mathrm{cm})$ & $138.4(15.5)$ & $138.7(15.0)$ \\
BMI $\left(\mathrm{kgm}{ }^{-2}\right)$ & $17.5(3.8)$ & $17.9(3.8)$ \\
FM $(\mathrm{kg})$ & $13.2(6.8)$ & $13.2(6.9)$ \\
Percentage FM $(\%)$ & $37.5(10.4)$ & $36.0(10.2)$ \\
Triceps SFT & $15.9(6.5)$ & $15.3(6.0)$ \\
Subscapular SFT & $15.3(9.4)$ & $15.7(9.4)$ \\
Supra-iliac SFT & $19.4(9.5)$ & $19.7(10.8)$ \\
Biceps SFT & $10.1(5.0)$ & $9.8(4.8)$ \\
\hline
\end{tabular}

$\mathrm{p}<0.05$ comparison between groups with in each gender

Table 2. Preliminary SFT, gender combined and gender specific equations for the prediction of FM and \%FM derived from validation group

\begin{tabular}{|c|c|c|c|}
\hline & Equation & $R^{2}$ & $R M S E^{a}$ \\
\hline \multicolumn{4}{|c|}{ FM prediction equations } \\
\hline FM & $\begin{array}{l}\text { Gender nonspecific } \\
(0.6 \times \text { age })+(0.198 \times \text { SFT-Tricep })+(0.353 \times \text { SFTSS })- \\
(2.28 \times \text { Sex Code })-1.43\end{array}$ & 70.2 & 3.7 \\
\hline $\begin{array}{l}\text { FM male } \\
\text { FM female }\end{array}$ & $\begin{array}{l}\text { Gender specific } \\
(0.63 \times \text { age })+(0.433 \times \text { SFT-Tricep })+(0.162 \times \text { SFTSS })-4.74 \\
(0.579 \times \text { age })+(0.039 \times \text { SFT-Tricep })+(0.55 \times \text { SFTSS })-0.52\end{array}$ & $\begin{array}{l}67.7 \\
68.5\end{array}$ & $\begin{array}{l}3.4 \\
3.9\end{array}$ \\
\hline \multicolumn{4}{|c|}{ Percentage FM prediction equations } \\
\hline Per FM & $\begin{array}{l}\text { Gender nonspecific } \\
30.93-(0.402 \times \text { age })+(0.409 \times \text { SFT-Tricep })+ \\
(0.254 \times \text { SFTSS })-(9.238 \times \text { Sex Code })\end{array}$ & 40.8 & 8.97 \\
\hline $\begin{array}{l}\text { Per FM male } \\
\text { Per FM female }\end{array}$ & $\begin{array}{l}\text { Gender specific } \\
14.789-(0.201 \times \text { age })+(1.26 \times \text { SFT-Tricep })-(0.23 \times \text { SFTSS }) \\
38.75-(0.533 \times \text { age })-(0.455 \times \text { SFT-Triep })+(0.731 \times \text { SFTSS })\end{array}$ & $\begin{array}{l}38.2 \\
19.5\end{array}$ & $\begin{array}{l}7.8 \\
9.5\end{array}$ \\
\hline
\end{tabular}


Table 3. FM and \%FM assessed by criterion method and each of the preliminary SFT prediction equations from cross validation

\begin{tabular}{|c|c|c|c|c|}
\hline Method of assessment & $\begin{array}{l}\text { Mean } \\
(S D)\end{array}$ & $\begin{array}{l}\text { Correlation }^{a} \\
\text { (r) }\end{array}$ & $\begin{array}{l}\text { Mean bias } \\
(S D)\end{array}$ & Pure error \\
\hline \multicolumn{5}{|l|}{ Fat Mass (kg) } \\
\hline \multicolumn{5}{|l|}{ Male $(n=53)$} \\
\hline Criterion method $\left(\mathrm{D}_{2} \mathrm{O}\right)$ & $9.3(7.8)$ & & & \\
\hline FM common equation & $8.6(5.8)$ & $0.946^{*}$ & $-0.78(2.9)$ & 3.0 \\
\hline FM male equation & $8.4(5.8)$ & $0.946^{*}$ & $-0.86(3.0)$ & 3.1 \\
\hline \multicolumn{5}{|l|}{ Female $(n=41)$} \\
\hline Criterion method $\left(\mathrm{D}_{2} \mathrm{O}\right)$ & $13.2(6.9)$ & & & \\
\hline FM common equation & $13.2(4.9)$ & $0.822 *$ & $0.03(4.0)$ & 3.9 \\
\hline FM female equation & $14.5(5.9)$ & $0.799^{*}$ & $1.38(4.2)$ & 4.3 \\
\hline \multicolumn{5}{|l|}{ Percentage FM } \\
\hline \multicolumn{5}{|l|}{ Male } \\
\hline Criterion method $\left(\mathrm{D}_{2} \mathrm{O}\right)$ & $26.2(12.0)$ & & & \\
\hline$\%$ FM common equation & $25.8(5.2)$ & $0.884^{*}$ & $-0.4(8.3)$ & 8.3 \\
\hline$\%$ FM male equation & $25.5(7.3)$ & $0.881 *$ & $-0.7(7.5)$ & 7.6 \\
\hline \multicolumn{5}{|l|}{ Female } \\
\hline Criterion method $\left(\mathrm{D}_{2} \mathrm{O}\right)$ & $36.0(10.2)$ & & & \\
\hline$\%$ FM common equation & $37.1(4.5)$ & $0.608 *$ & $1.1(9.7)$ & 9.7 \\
\hline$\%$ FM female equation & $37.8(5.0)$ & $0.407 * *$ & $1.8(9.8)$ & 9.5 \\
\hline
\end{tabular}

$* \mathrm{p}<0.001 \quad * *<0.01 \quad{ }^{a}$ Correlation between criterion method and assessments made using each of the prediction equations

Table 4. Final SFT, gender combined prediction equation for FM and \%FM

\begin{tabular}{lcclc}
\hline Equation & \multicolumn{2}{c}{ Goodness of fit } & \multicolumn{2}{c}{ PRESS procedure } \\
\cline { 2 - 5 } & $R^{2}$ & $R M S E$ & $\begin{array}{l}\text { PRESS statistic } \\
(\text { PRESS residuals })\end{array}$ & PRESS R \\
\hline $\begin{array}{l}\mathrm{FM}=(0.68 \times \text { Age })+(0.246 \times \text { SFT-Tricep })+ \\
(0.383 \times \text { SFTSS })-(1.61 \times \text { Sex Code })-3.45\end{array}$ & 76.4 & 3.4 & $3.4(1.5)$ & 75.6 \\
$\% \mathrm{FM}=(-0.28 \times$ Age $)+(0.49 \times$ SFT-Tricep $)+$ & & & & \\
$(0.34 \times$ SFTSS $)-(7.94 \times$ Sex Code $)-26.8$ & 46.9 & 8.6 & $8.7(2.6)$ & 44.8 \\
\hline
\end{tabular}


a)

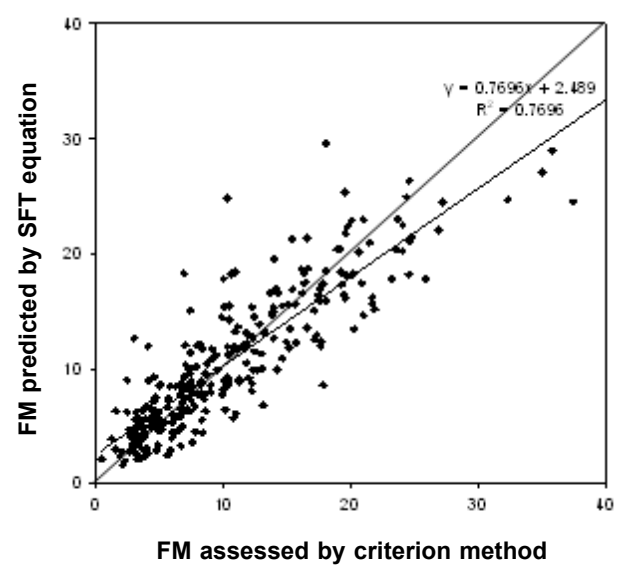

c)

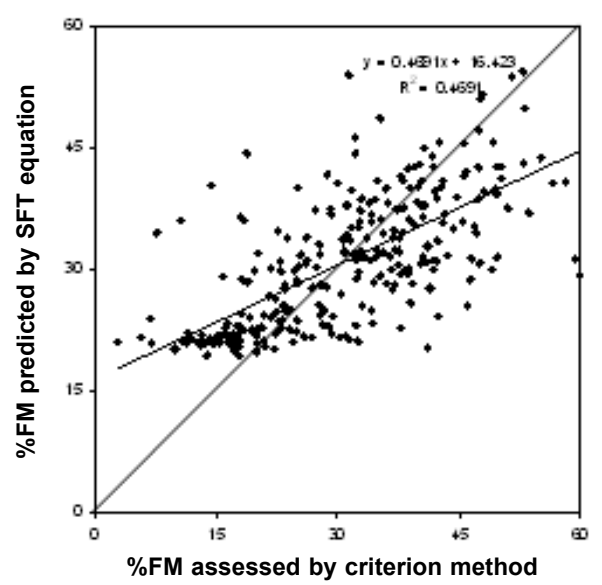

b)

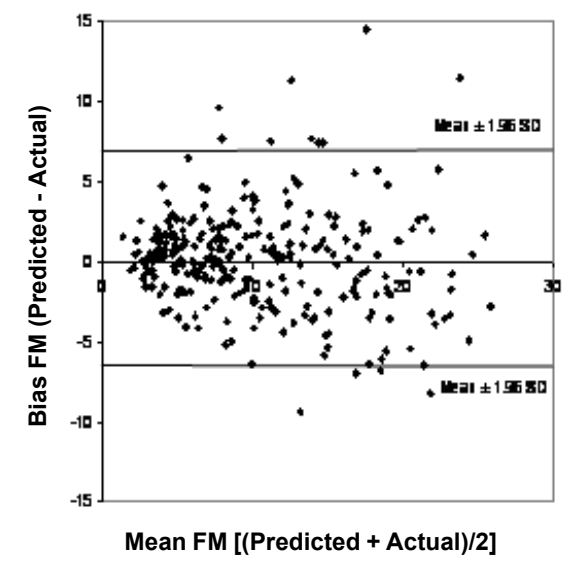

d)

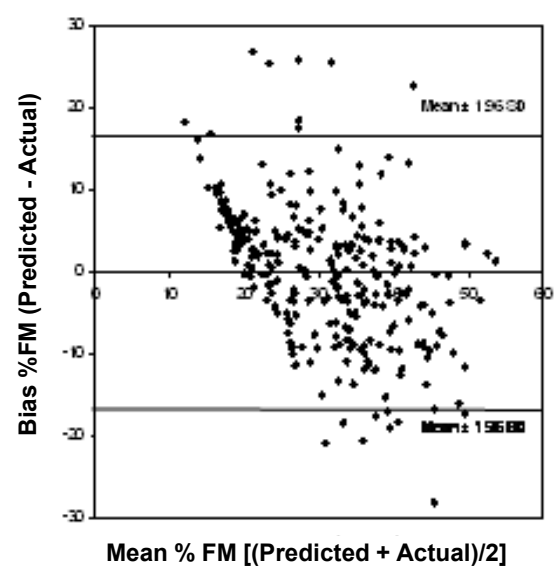

Figure 1. Predicted versus criterion method assessed, a) regression line for FM; b) Bland and Altman plot for FM; c) regression line for \%FM and d) Bland and Altman plot for \%FM.

\section{Discussion}

Prevalence of obesity is on the rise. Morbidity associated with obesity is related to the fat content of the body [12]. Therefore follow up of obese patients should be based on changes of $\% \mathrm{FM}$. To improve the diagnosis and treatment of obesity a set of body fat percentile charts have been developed for British children [13]. Most methods used for the assessment of body fat content are not practical in epidemiological or busy clinic settings. SFT is a method that could be used in such situations. The equation derived to estimate FM has shown good agreement more than the equation derived to estimate $\%$ FM.

Body composition assessment with SFT is based on validated prediction equations derived using statistical methods rather than biological properties of human physiology. Hence it is important to choose the appropriate equation to convert the SFT measurement to a body composition parameter. The prediction equations derived from populations which are closely linked to the population under study is the best. As most of the existing equations are validated on white Caucasian populations, it is important to either derive a set of equations or cross validate the existing equations on the target population prior to its clinical use. Sex specific equation did not show any improvement in the prediction of FM and $\% \mathrm{FM}$. We believe that having a gender combined single equation would be more practical in day to day practice. As there are no validated equations on south Asian populations, which would be the closest to Sri Lankan children, we did not have any data to compare our results.

Multi-component body composition assessment is considered the best technique for assessment of body composition. However, it needs more sophisticated equipment and sometimes errors could summate giving a greater error than 2-compartment body composition model. Isotope dilution technique is shown to be a reliable method in the assessment of TBW and hence body composition based on 2-compartment technique. 


\section{Conclusion}

SFT has paved the way for rapid assessment of body composition to satisfy epidemiological and clinical needs. Body composition shows significant differences between races, so that body composition assessment techniques should be validated to suit populations. We were able to validate two separate gender combined SFT equations to assess FM and \%FM of 5-15 year old Sri Lankan children. To our knowledge there are no SFT data for south Asian populations in the published literature. Lack of data from similar populations in the south Asian region has made it impossible to compare the results of this study. Results of this study need to be affirmed by more studies using multicomponent body composition assessments.

\section{Acknowledgements}

We are grateful to all children and their parents for participating in this study, and to Dr Samanmali Sumanasena for assisting to collect data from female participants. This study was carried out with financial support from the Children's Nutrition Research Centre, Department of Paediatrics and Child Health, University of Queensland, Brisbane, Australia.

\section{References}

1. Owen GM. Measurement, recording and assessment of skinfold thickness in children and adolescence: report of a small meeting. American Journal of Clinical Nutrition 1982; 35: $629-38$.

2. Janz KF, Nielsen DH, Cassady SL, Cook JS, Wu Y et al. Cross-validation of the Slaughter skinfold equations for children and adolescents. Medicine and Science in Sports and Exercise 1993; 25: 1070-6.

3. Reilly JJ, Wilson J, Durnin JVGA. Determination of body composition from skinfold thickness: a validation study. Archieves of Disease in Childhood 1995; 73: 305-10.
4. Wickramasinghe VP, Cleghorn GJ, Edmiston KA, Davies PSW. Impact of ethnicity upon body composition assessment in Sri Lankan Australian children. Journal of Paediatrics and Child Health 2005; 41: 101-6.

5. Wickramasinghe VP, Lamabadusuriya SP, Cleghorn GJ, Davies PSW. Use of skinfold thickness in Sri Lankan children: comparison of several prediction equations. Indian Journal of Paediatrics (In press, 2008).

6. Harrison GG, Buskirk ER, Carter JEL, Johnston FE, Lohman TG, et al. Skinfold thicknesses and measurement technique. In: Anthropometric standardization reference manual. Eds: Lohman TG, Roche AF, Martorella R. Human Kinetics, Champaign IL. 1988; 55-80.

7. Bell NA, McClure PD, Hill RJ, Davies PSW. Assessment of foot-to-foot bioelectrical impedance for the prediction of total body water. European Journal of Clinical Nutrition 1998; 52: 856-9.

8. Halliday D, Miller AG. Precise measurement of total body water using trace quantities of deuterium oxide. Biomedical Mass Spectrometry 1977; 4: 82-7.

9. Lohman TG. Assessment of body composition in children. Pediatric Exercise Science 1989; 1: 19-30.

10. Wickramasinghe VP, Lamabadusuriya SP, Cleghorn GJ, Davies PSW. Assessment of body composition in Sri Lankan children: validation of a bioelectrical impedance prediction equation. European Journal of Clinical Nutrition advanced online publication. 15 August 2007; doi:10.1038/sj.ejcn. 1602835.

11. Bland JM, Altman DG. Statistical methods for assessing agreement between two methods of clinical measurement. Lancet 1986; 326: 307-10.

12. WHO, 2000. Obesity: preventing and managing the global epidemic. WHO Technical Report Series 894, WHO Geneva.

13. McCarthy HD, Cole TJ, Fry T, Jebb SA, Prentice AM. Body fat reference curves for children. International Journal of Obesity Related Metabolic Disease 2006; 30: 598-602.

\section{The Cottage Hospital}

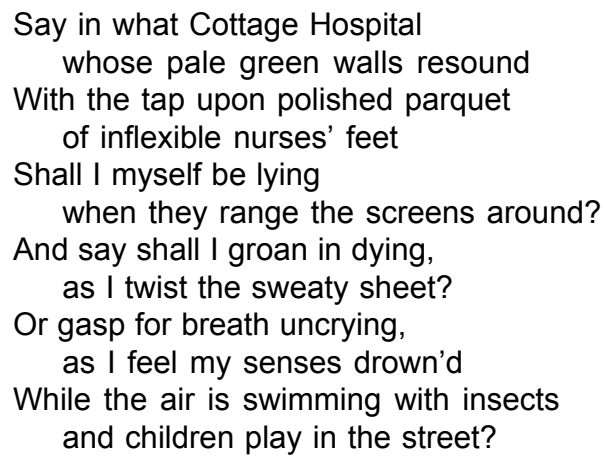

From The Cottage Hospital by Sir John Betjeman, English Poet Laureate from 1972 (1906-1978) 